all touched upon. Throughout his lecture, Dr. Simpson stressed the uncertainty of prophecy in these matters, but his exception of weather forecasting caused amusement. Most of the learned societies of the district were represented in the audience, which was highly appreciative of the visit.

\section{Neon Signs}

The discharge tubes used for advertising are a development of the old Geissler and Crookes tubes in which various beautiful effects were produced when evacuated tubes filled with certain gases were excited by an induction coil. In the January Engineering Supplement to the Siemens Magazine, there is an interesting article on the construction and the physical theory of commercial discharge tubes by E. A. Beavis. Forty years ago, the gases used were mostly nitrogen and carbon dioxide, and these required continual replenishing. It was only when the rare gases, argon, neon, helium, etc., were experimented with that it was found possible to obtain a reasonably permanent luminous discharge. These gases are not subject to absorption to anything like the same extent as the commoner gases. Neon at a suitable pressure gives more visible light and has a lower electrical resistance than the other permanent gases and hence a greater length of tubing can be operated for a given voltage. Neon has a cheerful red glow, argon gives a faint lavender colour and has little luminosity, and helium has a whitish glow. Combinations of various gases and vapours with neon and the use of coloured glass tubes have enabled many striking and pleasing coloured effects to be obtained. The positive column extending to the anode forms the main region of luminosity in the tube. By mixing traces of impurity in the gas, it is possible to obtain narrow cords of light which move within the tube and give rise to the type of discharge known as the 'ripple neon'. Sometimes also the column of light splits up into rows of coloured discs which often rotate round the axis of the tube. These effects are known as 'striations'. Alternating current is used for operating commercial tubes. As the voltage absorbed under running conditions is about 200 volts per foot of tube, it is usually divided up into a number of sections each supplied by a separate transformer.

\section{Banting Research Foundation, Toronto}

THIs foundation arose out of the desire to com. memorate the discovery of the active principle of the islets of the pancreas by Dr. F. G. Banting in 1921-22, and has received wide financial support in Canada. It has now been in active operation for six and a half years, though in the first two years the full capital sum was not available and the number of grants made were few. The capital sum now amounts to about 700,000 dollars and the number of individual grantees has steadily increased. The total number of grants made during the period is $\mathbf{9 2}$. These have been distributed to 63 workers in the following universities: Alberta 4, Saskatchewan 2, Dalhousie 8, Queen's 2, Western Ontario 2, Manitoba 16, McGill 26, Toronto 30 and 2 non-university.
Some fifty papers have already appeared in scientific publications, while a further fifteen are in press or ready for publication. Several pieces of work are not as yet complete. In accordance with its charter, the Foundation also aids in the support of the Department of Medical Research, University of Toronto (Dr. F. G. Banting) and from this source numerous papers on silicosis, the action of vitamins and other topics have appeared. During the past year twenty workers received grants from the fund. The Foundation, which is the only one in Canada giving support to medical research, has proved a valuable aid and stimulus to such research in that country. The world economic depression has increased the demands upon the Foundation, the trustees of which would welcome a larger revenue. Correspondence should be addressed to the Banting Research Foundation, Toronto, Canada.

\section{Reptile Skins in Commerce}

A FEw years ago the use of the skins of reptiles in the manufacture of shoes was regarded as a whim of the moment, but now the view is strongly held by the leather trade and by technical experts in the industry that the skins are established as a raw material for leather production on as permanent a basis as goat, calf and sheep skins. This is the view expressed by the sub-committee appointed by the Imperial Institute Advisory Committee on Hides and Skins (Bull. Imp. Inst., 31, No. 2, 160 ; 1933). The change in outlook has taken place since 1926, when reptile skins were employed only in the making of luxury articles; now they are used for the massproduction types of shoes, as well as for bag and fancy leathers. Some of the advantages of reptile leather are that it is hard-wearing, stronger than sheep, goat or even calf skins; it shows great variety of pattern and design; and it takes colour readily. But the demand has been telling upon reptile populations in various tropical countries. In 1932, India exported $2 \frac{1}{2}$ million reptile skins; in 1931, more than two million came from the Dutch East Indies; and serious depletion has occurred in the stock of the North American alligator, the edible terrapins of the United States, and the green turtle, the last being valued as food. An exhibition of reptile skins and their products will be opened at the Imperial Institute on February 12 at noon by Lieut.-Col. J. Colville, Parliamentary Secretary to the Department of Over. seas 'Trade.

\section{Eton College Natural History Society}

IT is encouraging to find that in the public schools of Great Britain there is no sign of declining interest in field studies. The expeditions held on holidays and half-holidays by the Eton College Society are excellent as introductions to natural history, and may lead to the more individual interest which is revealed in the lists of records, of lectures, and of museum preparations mentioned in the annual report for 1932-33. The report is enlivened by photographs taken by the members, and a list of Lepidoptera from the Eton district, by Brigadier-General B. H. Cooke, should be useful as a check-list for youthful collectors. 